\title{
Los Santos Padres de América Latina
}

\author{
José Comblin, \\ Bayeux, Brasil.
}

\section{Aproximación histórica}

\subsection{Los padres de la antigua Iglesia}

En la antigüedad, el nombre de Padre era dado a los maestros, a los que enseñaban. Así dice san Pablo: "Aunque hayan tenido diez mil pedagogos, en Cristo no han tenido muchos padres. He sido yo que, por el Evangelio, los engendré en Cristo Jesús" (1Cor 4, 15).

En la vida común, el título de padre podía ser dado a todos los maestros. Pero hay que tener en cuenta que hay una distinción entre pedagogo y maestro. $\mathrm{El}$ pedagogo es el que trasmite informaciones, comunica instrucciones. El maestro es el que educa para la vida, el que trasmite un mensaje de vida. Para los cristianos, el título de maestro y de padre tiene todavía más valor. Maestro y padre es aquella persona que, por el evangelio, engendra para la vida verdadera, el que comunica el mensaje de Jesús de modo vivencial.

Al principio, el nombre de Padre fue otorgado a ciertos obispos, porque los obispos eran los que enseñaban. Más tarde, otros fueron llevados también a enseñar y se les dio también el título de Padre de la Iglesia. Algunos recibieron un título de Padre por excelencia. En occidente, desde Bonifacio VIII, se reconoce como los santos padres por excelencia a san Agustín, san Ambrosio, san Jerónimo y san Gregorio. Son los cuatro pilares de la tradición latina. Los griegos veneran a tres: san Basilio, san Gregorio Nazianzeno y san Juan Crisóstomo. Los occidentales les añaden a san Atanasio, de modo que son cuatro y cuatro. Pero el título no es exclusivo.

Tradicionalmente, se identifica a los santos padres por cuatro caracteres: la ortodoxia, la santidad de vida, la aprobación de la Iglesia y la antigüedad. Son 
los que por su enseñanza vital han engendrado, en la fe, a los discípulos de Jesús. Los santos padres son quienes han configurado la Iglesia, en una cultura determinada.

Es importante recalcar que ellos no son padres de la Iglesia por sus enseñanzas personales, por su teología personal, por la fuerza de sus argumentos, sino porque, en su vida y en sus enseñanzas, trasmitieron auténticamente el mensaje de Jesús tal como lo habían recibido generaciones de verdaderos discípulos. No son padres por su individualidad, sino porque expresaron la fe y la vida del pueblo de Jesucristo. En ellos se expresaba la fe, la esperanza, la caridad de su pueblo. Ellos eran la voz del pueblo de Dios. Y el pueblo se reconocía en ellos. Eran la tradición viva del pueblo de Dios.

Entre los criterios que los definen está la antigüedad. En realidad, antigüedad no significa cercanía temporal a Jesús. Los santos padres no fueron quienes vivieron temporalmente más cercanos a Jesús. Ellos vivieron 300 años - y aun más-, después de Jesús. No fueron tampoco los fundadores de sus iglesias particulares. Sus iglesias ya tenían siglos de existencia. Pero surgieron en una época de desarrollo, en la cual la Iglesia tomó su figura característica. Aparecieron en un momento significativo para la historia de su pueblo. Por eso, ellos definieron, de alguna manera, la imagen de la Iglesia para siglos futuros. Así fue en la Iglesia griega y así fue en la Iglesia latina. Secundariamente, hubo también santos padres en iglesias que históricamente tuvieron una menor difusión: las iglesias de Siria, Armenia, Egipto, y otras que se expresaron en sus propios idiomas.

Desde entonces, aparecieron nuevas iglesias, en otros contextos culturales, por extensión de las iglesias de los orígenes. Durante siglos, pudieron permanecer sin originalidad, como pura extensión de las iglesias latina o griega. Fue el caso de las iglesias europeas que, históricamente, proceden de la iglesia griega 0 de la iglesia latina del tiempo de los santos padres.

\subsection{Los padres de la Iglesia latinoamericana}

En la época moderna surgió América Latina. En el siglo XVI, trabajaron como evangelizadores personajes que tendrían muchas de las características de los santos padres. Fueron los misioneros españoles, cuyos nombres fueron citados, aunque de modo no exhaustivo, en el documento de Puebla: "Antonio de Montesinos, Bartolomé de Las Casas, Juan de Zumárraga, Vasco de Quiroga, Juan del Valle, Julián Garcés, José de Anchieta, Manuel da Nóbrega, Toribio de Mogrovejo, Pedro Claver, Luís Beltrán, Rosa de Lima, Martín de Porres".

Fueron una vanguardia, pero sin un pueblo cristiano para sostenerlos. Después de ellos, sus trabajos se apagaron, y los reyes de España y Portugal establecieron una Iglesia, que no era sino una copia fiel de las iglesias ibéricas. Hasta el siglo $\mathrm{XX}$, las elites que gobernaron América Latina quisieron hacer de sus naciones 
reproducciones fieles de las naciones europeas. Sentían vergüenza de su propia cultura específica y querían prolongar la cultura europea. Sólo a mediados del siglo $\mathrm{XX}$, apareció una nueva generación que quiso independizarse de la cultura europea. En la Iglesia aparecieron personas proféticas que quisieron vivir el evangelio, a partir de los retos de su cultura, de su pueblo y de su destino histórico. La consecuencia fue la configuración de una nueva expresión del cristianismo, distinta, tanto de la Iglesia latina, como de la Iglesia griega.

Podemos decir que la Iglesia latino-americana adquirió una figura propia, en la segunda mitad del siglo XX, y se puso junto a la Iglesia griega y la Iglesia latina, y las iglesias orientales, como una nueva entidad histórica con figura propia, como nueva expresión de la tradición cristiana.

La tradición latinoamericana no nació del Vaticano II, pero el Vaticano II le permitió expresarse, en forma pública, en la Iglesia, aunque con muchas resistencias, por parte de la curia romana. Por supuesto, ésta quisiera que las iglesias latinoamericanas - como las iglesias europeas - quedaran totalmente configuradas por la Iglesia romana. La curia tiene miedo a perder ahora, en América Latina, la misma hegemonía, que ejerce en Europa y ejerció durante siglos en las tierras conquistadas por los europeos. El Vaticano II abrió, durante algunos años, un espacio suficiente para que se expresara una nueva figura de Iglesia, la cual difícilmente se podría apagar. Y una vez constituida, esa figura de Iglesia permanecerá en la memoria de los pueblos latinoamericanos. No se podrá volver a la situación anterior de colonia religiosa de Europa. La curia romana está haciendo todo lo posible para suprimir lo nuevo del Vaticano II, pero la historia no se suprime con tanta facilidad.

Los santos padres de América Latina ya actuaban cuando empezó el Concilio Vaticano II. Algunos tuvieron una actuación importante dentro del concilio. Sin embargo, el concilio les ofreció, en primer lugar, una posibilidad para encuentros paralelos. Fue en los pasillos del concilio donde se articuló el grupo de los que en la actualidad nosotros llamamos santos padres. El Vaticano II fue todavía un concilio de la Iglesia latina. Pero, a partir de él, hubo una oportunidad histórica para que los latinoamericanos tomaran conciencia de su peculiaridad. Lo mismo sucederá un día con las iglesias de África y Asia, pues éstas todavía no estaban maduras en aquel tiempo.

\subsection{Los contextos histórico-culturales}

Los santos padres de la Iglesia griega tienen algo en común: la confrontación con la cultura griega, sobre todo con la filosofía griega dominante en su época, el neo-platonismo. Consciente o inconscientemente, todos presentan una figura del cristianismo que es muy mística o que constituye una respuesta cristiana a un reto neo-platónico. Toda la tradición monástica es una defensa contra el influjo de la filosofía. Pero esta defensa supone, ella misma, una dependencia. El cristia- 
nismo griego es místico, profundamente religioso en el sentido místico. Su misma liturgia tiene un sentido místico acentuado. Sus santos padres dieron figura a esta presencia cristiana, en medio de una cultura mística, lo que en aquel tiempo se llamaba filosofía es mística.

En la Iglesia latina, la figura que prevaleció fue la de san Gregorio. La nota característica de la Iglesia latina es la organización, el derecho, las leyes. Los latinos hicieron del cristianismo una colección de leyes doctrinales, litúrgicas, estructurales. Existió también el influjo del neo-platonismo, por medio de san Agustín, pero lo que predominó históricamente fue la organización alrededor de la Iglesia romana, que, después de siglos de conquista paciente y perseverante, se constituyó como la administración centralizada de todas las iglesias.

También en América Latina existió un reto común, asumido simultáneamente, en todos los países. No hubo nada planificado, desde el comienzo. En forma independiente, surgieron figuras en México, Centroamérica, Colombia, Ecuador, Perú, Chile, Argentina, Bolivia, Paraguay, Brasil y el Caribe. Sin embargo, algo profundo tenían en común: los que llegarían a ser los padres de la Iglesia latinoamericana, entendieron la vida cristiana como respuesta al reto de la pobreza de sus pueblos. Partieron de la conciencia de que esa pobreza venía de la conquista y de la esclavitud, que era una estructura humana y que era expresión de la dominación de entidades políticas, las cuales se decían cristianas.

Todos estaban escandalizados por lo que se hacía en nombre del cristianismo y apelando a una legitimidad cristiana. Todos quisieron rectificar esa historia y revelar el verdadero mensaje de Jesús como llamado a la libertad, anuncio de un mundo nuevo de fraternidad sin dominación. La palabra justicia, palabra tabú en sus países, puede resumir la situación en que plantearon la evangelización. No puede haber evangelización en América Latina sin hablar de la justicia. En un mundo en el cual el ser humano es dominado, explotado o excluido estructuralmente con cobertura cristiana, el silencio sobre la justicia es traición al verdadero cristianismo.

Ahora bien, durante 400 años, esto había sido silenciado en América Latina. Cuando algunos empezaron a decir lo que era el verdadero mensaje de Jesús, aquello fue un despertar, como el surgir de una nueva Iglesia. Fue como si la Iglesia despertara de un largo sueño y empezara a existir realmente. Lo sorprendente fue que esto sucedió de forma simultánea en todos los países, creando un estilo homogéneo. Cuando los nuevos santos padres se encontraban en asambleas o reuniones más privadas, descubrían que todos ellos estaban en la misma onda, en el mismo camino, con la misma conciencia, a pesar de la diversidad de las situaciones de sus países. Cada cual había empezado solo, pero sin saberlo, todos eran movidos por el mismo Espíritu. 
No hubo teólogos entre ellos y la doctrina no estuvo en el centro de sus preocupaciones. Eran conductores de una Iglesia renovada, profetas al frente del pueblo de los oprimidos. Todos habían asumido un compromiso y habían roto con la injusticia establecida. Por eso, todos fueron perseguidos por los dominadores de su país. Su mensaje era práctico, tenía por objeto la vida, la dignidad, la libertad de sus pueblos, oprimidos por cristianos bautizados. En cierto modo, todos habían pasado por una conversión, pasaron de una figura de Iglesia a otra. Dicho con mayor precisión, con su conversión, crearon una nueva figura de Iglesia.

Algunos de ellos se habían encontrado en el Congreso Eucarístico Internacional de Río de Janeiro, en 1955, cuando se fundó el CELAM. A la base de esta fundación estaban don Manuel Larraín y don Helder Câmara, los principales líderes del nuevo episcopado, dos santos padres por excelencia. Los dos animaron juntos el CELAM hasta la muerte accidental de don Manuel, en 1966. Los dos prepararon la asamblea de Medellín de 1968.

Varios de nuestros santos padres se encontraron en las asambleas del CELAM. Los que ya eran obispos se encontraron en el concilio. Don Manuel Larraín conocía muy bien el episcopado de la América hispánica y supo juntar a los más representativos, en el CELAM, donde trabajaron, en diversas comisiones, Ramón Bogarín, Leonidas Proaño, Samuel Ruiz, Cândido Padin y otros. Fueron los que prepararon la conferencia de Medellín.

Medellín es un símbolo, una referencia permanente y quedará en la historia como marco histórico, como la fundación de una nueva trayectoria histórica. Evidentemente, la curia romana reaccionó, pero no logró apagar ese símbolo. En Puebla, hubo una lucha abierta entre los obispos de Medellín y los defensores de la curia romana. La conferencia terminó con un empate técnico, pero los textos positivos, en el sentido de Medellín, fueron suficientes para que Puebla también fuera símbolo. En 1992, la Cuarta Asamblea General del CELAM ya fue manipulada completamente por los delegados de la curia romana. De ella no salió nada.

El hecho de que la V Conferencia se realizará en Roma, en 2007, permite prever, con toda seguridad, que será la expresión fiel de la doctrina de la centralización romana y de su proyecto de suprimir de la historia el recuerdo de Medellín y Puebla. Pero esto es imposible. Ninguna nueva conferencia podrá apagar lo que se manifestó en Medellín y Puebla. Los fundamentos están puestos y nada podrá suprimir esa historia de la memoria de la Iglesia latinoamericana.

En Medellín y Puebla estuvieron reunidos los principales santos padres, quienes hablaron un lenguaje común. Sólo faltó don Manuel, fallecido prematuramente. No era necesario que la mayoría de obispos estuviera de acuerdo. En su día, la mayoría no estuvo en sintonía con los santos padres de la Iglesia griega o latina, pero éstos se impusieron con el tiempo, porque dieron las respuestas certeras a los retos verdaderos. De la misma manera, en América Latina, 
la mayoría de obispos no apoyó a los profetas que estaban a la vanguardia. Pero esa mayoría no tenía ningún proyecto, a no ser la repetición del pasado.

\section{Las notas que caracterizan a los santos padres}

La primera nota que caracteriza a los santos padres es su situación histórica, al comienzo de una nueva expresión de la Iglesia. Es lo que acabamos de mostrar, en el caso de América Latina.

La segunda nota es la santidad de vida. Sin duda alguna, los santos padres de América Latina fueron santos. Podemos incluso decir que inventaron un nuevo modo de santidad, y aquí también hubo una gran semejanza entre ellos. Todos ellos practicaron un amor apasionado hacia los pobres, los oprimidos. Fueron personas totalmente dedicadas a esa caridad. Su estilo de vida fue de lo más sencillo. Jamás pensaron en sus intereses particulares. Vivieron una vida siempre amenazada, perseguida, insegura, pero nunca se dejaron amedrentar, o deprimir, o desanimar por esa oposición. Muchas veces, se sintieron marginados dentro del mismo episcopado. Fueron mal juzgados, tenidos por sospechosos, maltratados, en Roma. Fueron acusados de políticos, más aún, de comunistas, de subversivos. La acusación más frecuente de la curia romana era que dejaban su diócesis en el peor desorden y se dedicaban a la política. Esta fue una constante. Era la acusación que los poderosos, sus adversarios, enviaban a Roma y, desafortunadamente, era acogida.

Los santos padres no tenían ningún interés político. No buscaban el apoyo de los políticos y no contaban con ellos para ayudar a los oprimidos a luchar de forma pacífica por su liberación. Eran muy pacíficos, amantes de la paz. Pero estaban muy conscientes de que no hay paz sin justicia. Sin violencia, sin provocación, pedían justicia y mostraron las injusticias estructurales, que las elites sociales y económicas de la nación no querían ver. Fueron héroes de la caridad.

En cuanto a las persecuciones que los acompañaban siempre, aguantaron todo sin amargura, sin rebelión, y continuaron fieles a su misión, a pesar de todo. A don Helder Câmara, Paulo VI le dijo un día: "Siga en su misión, pero yo no podré apoyarlo en público". El Papa tenía miedo a la curia, miedo de ser acusado de complicidad con los obispos subversivos y políticos. Fueron mártires de la justicia, o sea, mártires como defensores de los pobres y oprimidos. Algunos fueron muertos, como don Oscar Romero, a quien celebramos en estos días. Hubo otros antes que él, que también murieron asesinados, don Enrique Angelelli de La Rioja, y después de él, don Juan Gerardi de Guatemala, nuestra vecina. Otros fueron apresados. El acontecimiento más simbólico fue la prisión de diecisiete obispos, en Riobamba en agosto de 1976.

La tercera nota de los santos padres era la ortodoxia, en la fe. En esto, nuestros santos padres de América Latina nunca fueron criticados. Nunca se les 
encontró una apariencia siquiera de herejía. Trasmitieron la doctrina tradicional, en la forma latina, en la cual les fue comunicada. Nunca cuestionaron los dogmas, aprendidos en el seminario.

No eran teólogos y su preocupación principal no fue la de luchar contra posibles herejías. Es verdad que no se lanzaron a la lucha teórica contra el marxismo una obsesión romana durante la guerra fría. No eran marxistas, pero no creían que su vocación fuera luchar contra el marxismo. Más bien, pensaban, como el mismo Concilio Vaticano II, que el marxismo sacaba su fuerza de seducción de la ausencia de la Iglesia, en la opresión social del continente. Creían que la mejor forma de luchar contra el comunismo era luchar por la justicia, pues el comunismo se alimentaba de la persistencia de la injusticia estructural de la sociedad.

Hay una forma de ortodoxia a la cual dieron más valor: la ortodoxia en el seguimiento de Jesucristo. Eran fieles a todos los dogmas, pero lo que más los preocupaba era el mensaje y el ejemplo de Jesucristo. La cruz no la vieron tanto en el catecismo, sino más bien en su vida. Las bienaventuranzas, las enseñaban, pero sobre todo las vivían. El servicio a los pobres y marginados, no se contentaban con admirarlo, sino que lo vivían todos los días. La persecución, incluso de las autoridades eclesiásticas, no era para ellos recuerdo histórico, sino realidad sufrida casi permanentemente. Su referente constante era el mismo evangelio de Jesús. Esto también era común a todos. Todos daban más valor al amor que a la ley.

Jesús vivió una vida pública. Estaba, siempre estuvo expuesto a las agresiones de las autoridades y de los grandes de su pueblo. No fue un religioso escondido, en una celda discreta. No era hombre de pura oración, recluido en su eremitorio. Estaba en las plazas, en las calles, en los caminos, discutía con los doctores, con los fariseos, con los sacerdotes del templo. Fue una persona expuesta públicamente, porque hablaba de la ley, y denunciaba su prioridad.

De la misma manera, nuestros santos padres fueron personas públicas, expuestas. Siempre estaban en la plaza pública, expuestos a las críticas, a las denuncias, pero siempre criticaron y denunciaron. Estaban metidos en el gran juicio, que según san Juan, fue la línea maestra de la vida de Jesús. Siempre acusados y siempre acusadores como Jesús. Y tenían a su lado un abogado fuerte, capaz de desenmascarar a los abogados de la opresión. Era el Espíritu Santo, tal como Jesús lo había prometido.

No hablaban como profesores, ni como doctores, sino como abogados, defensores de los oprimidos, en el gran tribunal abierto por Dios para juzgar a este mundo, como lo muestra el cuarto evangelio. Jesús dio testimonio de la verdad, en contra de los que se decían representantes de la ley de Moisés. Los santos padres dieron testimonio de la verdad, en una sociedad que se decía cristiana y que, en realidad, oprimía a los pobres como lo hacían los adversarios de Jesús. 
Había un cuarto carácter que servía para identificar a un padre de la Iglesia. Era el reconocimiento por la Iglesia, es decir, por el pueblo cristiano. Era necesario que el pueblo los reconociera como sus verdaderos padres, en la vida cristiana. Más tarde, la Iglesia romana quiso centralizar todas las funciones y se consideró como representante del pueblo cristiano. Se atribuyó el monopolio de todas las distinciones, de todos los carismas. La Iglesia definió quiénes eran los santos y quiénes no lo eran. Al principio y durante siglos, el pueblo hacía eso. Los santos padres no fueron reconocidos como tales porque la Iglesia romana les atribuyera ese título. Ese les fue conferido por el pueblo.

¿Cómo podrían ser padres si no tuvieran hijos para reconocerlos como padres? En aquellos tiempos, las comunidades cristianas reconocieron y aclamaron a esos pastores, en quienes habían identificado el verdadero camino de Jesucristo. Para ellos, esas personas habían actuado y siguieron estrictamente el modelo de Jesucristo, en su circunstancia. No eran padres por sus talentos, por su personalidad, sino porque en ellos se reconocía la manifestación de Jesús, en la tierra.

En América Latina, sin duda, los santos padres han sido reconocidos, aclamados, venerados como verdaderos discípulos de Jesucristo, y por lo tanto, como maestros, en el camino de Jesucristo. Por supuesto, no fueron reconocidos por quienes se decían cristianos y, en realidad, eran cómplices de los opresores de los pobres. No fueron aclamados por los que vivían de la explotación de los pobres. Pero fueron reconocidos por los mismos pobres, por los indígenas, por los negros, por los campesinos pobres, por los refugiados en las miserables periferias de las ciudades. Este es el verdadero pueblo de Dios. Ellos son la verdadera Iglesia. Ellos tenían autoridad para reconocer a sus verdaderos padres.

Frecuentemente, nuestros santos padres sufrieron la incomprensión de varios colegas en el episcopado o la incomprensión y la oposición de la Iglesia romana. Sin embargo, ninguno fue condenado jamás, porque en el fondo, todos sabían que estaban en el buen camino, aunque muchos colegas no tuvieran fuerza moral suficiente para seguir su ejemplo. Aun así, siempre encontraron apoyo en el mismo episcopado. Eran motivos de división, y sucedió lo mismo que con Jesús. Jesús dividió la sociedad, en la que estaba: hermanos contra hermanos, padres contra hijos, vecinos contra vecinos. Es inevitable que así suceda. Un pastor que agrada a todos, probablemente no hace nada, cierra los ojos y nada dice de las injusticias del mundo, en el cual vive.

Tenían la aprobación del pueblo de los pobres y esta era la verdadera señal de su autenticidad. No se necesita ninguna otra autoridad para que sean reconocidos como verdaderos padres y maestros de la Iglesia, como fundadores de la Iglesia latinoamericana, el día que ella tomó conciencia de su particularidad y de su misión específica. 
Podríamos añadir que los santos padres son únicos y no tienen sucesores. Los fundadores no tienen sucesores. Son únicos. Después de ellos, cabe a sus Iglesias conservar la herencia, extender en el espacio y el tiempo el mensaje recibido. No hay que mirar hacia el cielo para ver si vienen otros semejantes. No vendrán. Pero cada cristiano se siente responsable de aplicar la lección recibida. Nadie tiene dos padres, como decía san Pablo. Uno solo basta para aprender a vivir.

Hasta aquí, no he citado nombres, salvo los nombres de los obispos mártires. No tengo autoridad para hacer una lista. No existe ninguna lista oficial. En cierto modo, en cada país todos saben quiénes son. No hay ninguna necesidad de hacer una lista completa. En ciertos casos, puede haber duda de si tal persona realmente tuvo la repercusión suficiente como para ser puesto en la lista de los santos padres. Por eso, no hay que hacer una lista completa. Es mejor dejar la cuestión abierta.

He mencionado a los mártires, en primer lugar, porque el martirio no admite ninguna duda. Al lado de ellos hay otras personalidades indiscutibles. Indiscutibles son los dos amigos que estuvieron al frente del movimiento, y definieron claramente su orientación: don Manuel Larraín, de Talca, Chile, y don Helder Câmara, de Recife, Brasil. Fueron los fundadores y los animadores del CELAM. Jugaron un papel predominante en el concilio y en la preparación de Medellín. En su país eran los conductores, aunque no tuvieran el puesto de presidente.

Hay otros nombres indiscutibles, sobre todo porque fueron reconocidos internacionalmente. Algunos todavía viven y no quiero citar nombres de personas que todavía están actuando, aunque ya tengan una edad avanzada. Entre los fallecidos, algunos son de fama internacional, reconocidos en el mundo, como obispos típicos de América Latina, más allá de las fronteras de su país: don Leonidas Proaño, de Riobamba, Ecuador, don Ramón Bogarín, de San Juan Bautista de las Misiones, Paraguay, don Sergio Méndez Arceo, de Cuernavaca, México, don José Dammert, de Cajamarca, Perú. No voy a citar los muchos nombres que en cada país se podrían citar, para no alargar a lista, sabiendo que algunos que todavía están con vida entrarán en ella.

De algunos de ellos ya se han publicado los escritos, como de don Manuel Larraín, don Oscar Romero. De otros, se ha iniciado la publicación: don Helder Câmara, don Leonidas Proaño, don Ramón Bogarín. Además, algunos ya habían publicado obras escritas durante su vida, como don Helder Câmara o don Leonidas Proaño. Juntando a esos nombres indiscutibles, hay por lo menos veinte nombres que dejaron un fuerte recuerdo y mostraron el camino, en su país, pero prefiero que el reconocimiento venga de cada país.

De los que he conocido personalmente, de modo un poco prolongado, lo suficiente para dar mi testimonio personal, entre los fallecidos, citaría a Fernando Ariztía y Enrique Alvear, de Chile, Jaime de Nevares de Neuquen, Argenti- 
na. De Brasil, tengo por lo menos unos seis o siete nombres en la mente, pero todos ellos están vivos todavía. Algunos cardenales dieron un apoyo significativo, aunque no hayan sido orientadores del movimiento: los cardenales Raúl 'Silva, de Santiago, Chile, el cardenal Juan Landázuri, de Lima, Perú, el cardenal don Avelar Brandão Vilela, de Salvador, Brasil. Los dos últimos fueron presidentes de la conferencia de Medellín.

En la actualidad, la orientación dominante en la Iglesia católica es otra. Pero esta fase histórica pasará, porque los fundamentos de la nueva Iglesia latinoamericana ya están colocados. A nosotros está reservada la misión de conservar y trasmitir el recuerdo de esos hombres para que puedan iluminar los siglos que vienen. Los retos de América Latina no serán superados en poco tiempo. Los caracteres de la sociedad y la cultura de América Latina no se apagarán, en poco tiempo. Está abierta una misión destinada a llenar siglos.

Muy necesaria es la publicación de las obras escritas de los santos padres, y la redacción de buenas biografías. Entonces vendrán muchos trabajos de exposición y aplicación del testimonio de los santos padres. Estudiantes y especialistas publicarán obras de análisis y de síntesis para que los tesoros escondidos estén abiertos y asequibles a todos los cristianos.

Habrá que evitar que la memoria se transforme en culto como sucedió tantas veces, en la antigua cristiandad. Podemos afirmar con toda tranquilidad que todos estos santos padres, que hemos conocido o todavía conocemos, se sentirían muy incómodos si supieran que se les va a dar un culto. Pero con la misma tranquilidad, podemos afirmar que desean con mucha fuerza que su tarea sea continuada sin cesar. 